\title{
Reply to the Letter to the Editor: "Olfactory nerve sparing technique for anterior skull base meningiomas: how I do it"
}

\author{
Paolo Ferroli $^{1} \cdot$ Francesco Restelli ${ }^{1}$ [D $\cdot$ Morgan Broggi ${ }^{1}$
}

Received: 21 December 2021 / Accepted: 22 December 2021 / Published online: 3 February 2022

(c) The Author(s), under exclusive licence to Springer-Verlag GmbH Austria, part of Springer Nature 2021

We thank Dr. Agosti and co-authors for their observations [1] concerning our previous "how I do it" article on olfactory nerve (olfN) sparing technique during surgical management of anterior skull base (ASB) meningiomas [2].

As correctly pointed out [1], the tuberculum sella (TS) anatomically belongs to the middle cranial fossa; it is also true that TS and planum sphenoidalis (PS) meningiomas usually do not present with olfactory dysfunction. Nevertheless, a detailed anatomical description of the ASB limits was not the primary objective of our technical note, which instead aimed at presenting the sparing technique of the olfNs when approaching all ASB meningiomas from a basal fronto-lateral approach. In fact, also in TS and PS meningiomas (especially in big ones), the olfNs, although still correctly functioning, can be severely compressed and stretched by the lesion being at concrete risk of damage during tumor removal, if not cautiously and delicately dissected as described [2].

Looking at the other points raised, we fully agree that in olfactory groove meningiomas, the rate of postoperative olfactory deficit is high, whatever surgical approach is used [1]. Concerning this aspect, our data are in line with those reported in the literature, especially when preoperative olfactory dysfunction is already present; this was clearly stated in our article in the "limitation" section. The low postoperative hyposmia and anosmia rates included all ASB meningiomas treated in the last 5 years and they were referred as "new onset" deficits. In other words, we are stating that, when the olfaction is intact, the proposed olfN sparing technique could reduce undesired and unexpected postoperative olfactory dysfunctions.

We are sincerely grateful to Agosti and co-authors for having raised the aforementioned important points, giving us the opportunity to better explain some aspects of our technical note, thus further improving the scientific value of the article; we hope that Acta Neurochirurgica readers will enjoy reading our "how I do it" article [2], along with this pleasant correspondence.

\section{Declarations}

Conflict of interest The authors declare no competing interests.

\section{References}

1. Agosti E, Alexander AY, Doglietto F, Fontanella MM (2021) Letter to the Editor: "Olfactory nerve sparing technique for anterior skull base meningiomas: how I do it." Acta Neurochir (Wien) in press

2. Ferroli P, Restelli F, Broggi M (2021) Olfactory nerve sparing technique for anterior skull base meningiomas: how I do it. Acta Neurochir (Wien) 163:2453-2457

Publisher's Note Springer Nature remains neutral with regard to jurisdictional claims in published maps and institutional affiliations.
This article is part of the Topical Collection on Tumor-Other

Francesco Restelli

francesco.restelli91@gmail.com

1 Department of Neurosurgery, Fondazione IRCCS Istituto Neurologico Carlo Besta, Via Celoria 11, 20133 Milan, Italy 